\title{
Comparison of clinical tests and the KT1000 in the diagnosis of anterior cruciate ligament rupture
}

\author{
G.P. Graham ${ }^{1}$ FRCS, S. Johnson ${ }^{2}$ MRCGP, C.M. Dent ${ }^{3}$ FRCS and J.A. Fairclough ${ }^{4}$ FRCS \\ ${ }^{1}$ Senior Registrar, Cardiff Royal Infirmary, Cardiff, UK \\ ${ }^{2}$ Research Assistant, Cardiff Royal Infirmary, Cardiff, UK \\ ${ }^{3}$ Registrar, Cardiff Royal Infirmary, Cardiff, UK \\ ${ }^{4}$ Consultant Surgeon, Cardiff Royal Infirmary, Cardiff, UK
}

\begin{abstract}
A prospective study was undertaken to compare the accuracy of the Lachman test, anterior drawer test and jerk test with the KT1000 knee arthrometer in patients with proven anterior cruciate ligament deficiency. The Lachman and anterior drawer tests were found to be the most accurate indicators of anterior cruciate ligament deficiency. The KT1000 knee arthrometer was found to be totally inaccurate, which precludes its use as an objective measure of anteroposterior laxity of the knee.
\end{abstract}

Keywords: Anterior cruciate ligament deficiency, clinical tests, KT1000 arthrometer

Anterior cruciate ligament deficiency is recognized as a common cause of morbidity among sportsmen. A number of clinical tests for anterior cruciate ligament laxity have been described and a variety of instruments to measure knee laxity in the anteroposterior plane are on the market. One such instrument is the KT1000 knee arthrometer (The MEDmetric Coporation, San Diego, California, USA). A recent report has cast doubt on the accuracy of the KT1000 knee arthrometer ${ }^{1}$. Our own experience on over 300 patients suggested that it is not as accurate as previously claimed ${ }^{2,3}$ and that clinical tests are a better way of diagnosing anterior cruciate ligament deficiency. In a prospective study we compared the accuracy of the anterior drawer test, the Lachman test and the jerk test with that of the KT1000.

\section{Patients and methods}

Over a 10 -week period all patients seen in a specialist knee clinic who were suspected on clinical grounds of having chronic complete anterior cruciate ligament tears were entered into the trial. Of 21 consecutive patients that were entered, all were later confirmed to have complete tears of the anterior cruciate ligament at arthroscopy.

All patients underwent clinical examination by the same experienced clinician to ensure consistency in

Address for correspondence: C. M. Dent, Department of Traumatic and Orthopaedic Surgery, Cardiff Royal Infirmary, Newport Road, Cardiff CF2 1SZ, UK

(C) 1991 Butterworth-Heinemann Ltd. 0306-3674/91/020096-02 the examination findings. The anterior drawer test was performed with the knee flexed to $90^{\circ}$ and the foot in the neutral position and a score of 0 (negative) -3 (positive) was given for the laxity. The Lachman test was performed as described by Torg et al. ${ }^{4}$ and was also scored out of 3 (positive). The jerk test was performed as described by Galway et al. ${ }^{5}$ and was scored as either positive, negative or equivocal. The normal knee was then examined in the same way.

Both knees were tested using the KT1000 arthrometer as described in previous reports on this device ${ }^{2,3}$. In keeping with our normal practice, each knee was tested twice with the arthrometer with a $5 \mathrm{~min}$ gap between the tests. The difference in the anterior displacement between the patient's normal and abnormal knee when a force of 89 newtons was applied was measured, and a mean of the two readings was taken. A difference of $2 \mathrm{~mm}$ was taken as significant. Before each reading it was ensured that the patient was relaxed and in particular that the quadriceps and hamstrings were relaxed. The machine was in good working order and reproducible measurements were obtainable with it. The operator was experienced with the machine, having used it on over 300 patients.

\section{Results}

The results are given in Table 1.

\section{Discussion}

Previous studies have found that the KT1000 knee arthrometer provides a sensitive measure of the integrity of the anterior cruciate ligament $t^{2,3}$. Our results support those of Forster et al. ${ }^{1}$ and cast doubt on the accuracy and usefulness of the KT1000.

In this study the KT1000 was accurate in only ten of 21 patients. The number of reversed findings (8/21) was high. The findings of the arthrometer cannot be correlated with the clinical findings, and this suggests that the reversed and equivocal arthrometer findings were not simply due to poor muscle relaxation; the clinical tests, particularly the anterior drawer, also require the patient to be relaxed. 
Table 1. Comparison of the clinical results and those with the KT1000 arthrometer

\begin{tabular}{|c|c|c|c|c|c|c|c|}
\hline \multicolumn{5}{|c|}{ Clinical } & \multicolumn{3}{|c|}{ KT1000 } \\
\hline No. & Side & $A D$ & Lachman & Jerk & Right & Left & Significance \\
\hline $\begin{array}{r}1 \\
2 \\
3 \\
4 \\
5 \\
6 \\
7 \\
8 \\
9 \\
10 \\
11 \\
12 \\
13 \\
14 \\
15 \\
16 \\
17 \\
18 \\
19 \\
20 \\
21\end{array}$ & $\begin{array}{l}\mathrm{L} \\
\mathrm{L} \\
\mathrm{L} \\
\mathrm{L} \\
\mathrm{L} \\
\mathrm{L} \\
\mathrm{L} \\
\mathrm{L} \\
\mathrm{L} \\
\mathrm{L} \\
\mathrm{L} \\
\mathrm{R} \\
\mathrm{R} \\
\mathrm{R} \\
\mathrm{R} \\
\mathrm{R} \\
\mathrm{R} \\
\mathrm{R} \\
\mathrm{R} \\
\mathrm{R} \\
\mathrm{R}\end{array}$ & $\begin{array}{l}2+ \\
2+ \\
3+ \\
2+ \\
3+ \\
2+ \\
2+ \\
3+ \\
3+ \\
2+ \\
2+ \\
2+ \\
2+ \\
3+ \\
2+ \\
3+ \\
2+ \\
3+ \\
2+ \\
3+ \\
3+\end{array}$ & $\begin{array}{l}1+ \\
1+ \\
3+ \\
2+ \\
3+ \\
2+ \\
2+ \\
3+ \\
2+ \\
1+ \\
2+ \\
2+ \\
3+ \\
3+ \\
3+ \\
3+ \\
2+ \\
2+ \\
2+ \\
3+ \\
3+\end{array}$ & $\begin{array}{l}\text { Eq } \\
- \\
+ \\
+ \\
+ \\
+ \\
+ \\
+ \\
+ \\
+ \\
+ \\
+ \\
+ \\
+ \\
+ \\
+ \\
- \\
+ \\
+ \\
+ \\
+\end{array}$ & $\begin{array}{r}2 \\
0 \\
5 \\
6 \\
0 \\
5 \\
2 \\
10 \\
12 \\
3 \\
4 \\
9 \\
8 \\
8 \\
2 \\
5 \\
1 \\
6 \\
5 \\
8 \\
2\end{array}$ & $\begin{array}{r}10 \\
5 \\
8 \\
8 \\
3 \\
10 \\
9 \\
5 \\
5 \\
1 \\
5 \\
4 \\
6 \\
3 \\
10 \\
15 \\
10 \\
10 \\
11 \\
7 \\
4\end{array}$ & $\begin{array}{l}\text { Correct } \\
\text { Correct } \\
\text { Correct } \\
\text { Correct } \\
\text { Correct } \\
\text { Correct } \\
\text { Correct } \\
\text { Reversed } \\
\text { Reversed } \\
\text { Reversed } \\
\text { Equivocal } \\
\text { Correct } \\
\text { Correct } \\
\text { Correct } \\
\text { Reversed } \\
\text { Reversed } \\
\text { Reversed } \\
\text { Reversed } \\
\text { Reversed } \\
\text { Equivocal } \\
\text { Equivocal }\end{array}$ \\
\hline
\end{tabular}

$A D$, anterior drawer; Eq, equivocal; +, positive; - , negative; $L$, left; $R$, right

All the patients in this small cohort had a positive anterior drawer test and Lachman test. However, in three cases the Lachman test was only mildly positive
$(1+)$ and may have been missed by a less experienced examiner. The jerk test was positive in 17 patients, equivocal in one, and negative in three. The four patients in whom the jerk test was not obviously positive were all apprehensive during the examination and could not relax. This apprehension is a common finding even in patients without anterolateral instability and cannot be taken to mean that the test will be positive under anaesthesia.

In this study the most accurate measures of anterior cruciate ligament laxity were the anterior drawer and Lachman tests. The jerk test was a less reliable indicator of anterior cruciate deficiency, particularly if the patient was apprehensive. The KT1000 was totally inaccurate and this precludes its use as an objective measure of anteroposterior laxity.

\section{References}

1 Forster IW, Warren-Smith CD, Tew M. Is the KT1000 knee ligament arthrometer reliable? J Bone Joint Surg [Br] 1989; 71-B: 843-7.

2 Daniel DM, Malcolm LL, Losse G, Stone ML, Sachs R, Burks R. Instrumented measurement of anterior laxity of the knee. $J$ Bone Joint Surg [Am] 1985; 67-A: 720-5.

3 Malcolm LL, Daniel DM, Stone ML, Sachs R. The measurement of anterior knee laxity after ACL reconstructive surgery. Clin Orthop 1985; 196: 35-41.

4 Torg JS, Conrad W, Kalen V. Clinical diagnosis of anterior cruciate ligament instability in the athlete. Am J Sports Med 1976; 4: 84-93.

5 Galway RD, Beaupré A, MacIntosh DL. Pivot shift: a clinical sign of symptomatic anterior cruciate insufficiency. J Bone Joint Surg $[B r]$ 1972; 54-B: 763.

It is with great sadness that we record the death, on February 12th, 1991 at the age of 61 , of Ronald James Pickering OBE, MEd. A BASM member since 1963, he achieved distinction as a National Coach in athletics and subsequently as a media commentator and public figure. His bonhomie, enthusiasm, humour and championing of athletics and, above all, fair play will not be forgotten by all who were privileged to work with him. 